\title{
Effect of the ethylene content on the properties m-polypropylene/EPDM blends
}

\begin{abstract}
Summary
Thermoplastic vulcanizates (TPV) were prepared with metallocene polypropylene $(\mathrm{mPP})$ and two different ethylene-propylene-diene (EPDM) polymers. The effects of different PP/EPDM relative concentrations, as well as the effect of ethylene content in the EPDM upon the crystallization and mechanical properties of the TPV were studied. It was found that the properties varied markedly with both, the PP/EPDM/relative concentrations and with the ethylene content on the EPDM. Overall, the EPDM with the higher ethylene content produced slightly better mechanical properties. Similarly, the optimum rubber concentration is determined for the preparation of the TPVs according to the final properties evaluated in said mixtures.
\end{abstract}

Keywords: versatile polymers. co-polymerization, polyethylene, cross linking, elastomers, sulfur cured, coagent, diene monomer
Volume I Issue I - 2017

\author{
Avalos BF,' Mendoza PC,' Ortiz CJC,' \\ Ramos VLF ${ }^{2}$ \\ 'Universidad Autónoma de Coahuila, México \\ ${ }^{2}$ Centro de Investigación en Química Aplicada (CIQA), México
}

Correspondence: $\mathrm{F}$ Avalos Belmontes, Universidad Autónoma de Coahuila, BlvdV Carranza y Cárdenas-Valdés, CP 25100 Saltillo, Coahuila, México, Tel 52-844- 4389830. Email favalos@uadec.edu.mx

Received: January 26, 2017 | Published: March 03, 2017
Abbreviations: MPP, metallocene poly propylene; TPV, thermoplastic vulcanizates; EPDM, ethylene propylene diene

\section{Introduction}

Due to its excellent all-around mechanical properties, PP is one of the more important and versatile polymers. It is amply used in the automotive industry, in many electric and electronic appliances, in construction, etc. However, its applications are somewhat limited due to its fragility, especially at low and very low temperatures. This has been overcome following two different approaches:

i. Via co-polymerization of propylene with some ethylene, reducing so the crystallinity and as a consequence, increasing the toughness of the E-P copolymer; and

ii. Via blending of PP with and elastomer, ${ }^{1}$ usually EPM or EPDM, which can be either used as a simple blend, or can be vulcanized. These latter materials are known as thermoplastic vulcanizates (TPV).

TPV usually consist of a soft crosslinkable phase (usually an elastomer) dispersed in a thermoplastic phase. The crosslinking can be carried out dynamically, in an internal mixer or in a twin screw extruder. ${ }^{2,3}$ or can be carried out statically, via compression molding.

TPV based on PP/EPDM have become very important, due first, to the high compatibility between the two phases, and second, because they can be processed at high melt temperatures. ${ }^{4-6}$ In addition, due to the diene monomer in saturation staying as a pendant group, outside of the main chain, the EPDM maintains the good oxygen and ozone aging resistance as polyethylene and polypropylene. ${ }^{7,8}$ TPVs are amply used in many applications due to their high environmental resistance, good mechanical properties, low density, and low cost. ${ }^{9}$

The higher the ethylene content the higher the filler loading possibilities of the polymer, and the better mixing and extrusion processing. Common crosslinking systems for PP/EPDM TPVs are the phenol-formaldehyde resins (resol-resins). However, these TPVs present two major problems. ${ }^{10}$

i. The high hygroscopicity of the TPV produced with this Crosslinking system ii. The appearance of a dark brown color, which is difficult to conceal. Crosslinking with peroxides is an alternative. However, when peroxides are used to crosslink a PP/EPDM blend, two competing processes take place simultaneously: EPDM-crosslinking and PP-degradation. ${ }^{11-13}$

Less common is the sulfur-curing system for the production of PP/ EPDM TPVs. However, Ilisch et al., ${ }^{14}$ for example, have reported that tensile strength increases while the storage modulus (E') decreases slightly, with increasing curing system concentration. Dynamically vulcanized sulfur-cured thermoplastic elastomers based on PP/ EPDM with varied blend-ratios, have been studied, and continue to be studied, by Katbab et al..$^{15-17}$ The dienes in the EPDMs, typically comprising from $2.5 \%$ up to $12 \%$ by weight of the composition, serve as crosslinks when curing with sulphur and resin, ${ }^{18}$ with peroxide cures the diene (or third monomer) functions as a coagent.

The excellent properties of the TPV have been attributed to the very specific microstructure attained through vulcanization, which consists of very minute, slightly vulcanized rubber particles, very well dispersed in a continuous thermoplastic phase. ${ }^{19-21}$ The purpose of the present work is to study the effects of different PP/EPDM concentrations, as well as the effect of ethylene content in the EPDM upon the crystallization and mechanical properties of a sulfur cured TPV.

\section{Experimental}

\section{Materials}

The polymers used were: a metallocene isotactic polypropylene, MR 2001, (mPP) from Atofina, USA, with a molecular weight Mw of 185,000 and a MFI of $25 \mathrm{~g} / 10 \mathrm{~min}\left(230^{\circ} \mathrm{C}\right.$ and $\left.2.16 \mathrm{~kg}\right)$; two EPDMs (NORDEL EPDMs), both with ca. $5 \mathrm{wt} \%$ of ethylidenenorbornene as the diene monomer, IP-4640 (EPDM-55) with an ethylene content of $55 \mathrm{wt} \%$ and a Mooney Viscosity $\mathrm{ML}(1+4)$ at $125^{\circ} \mathrm{C}$ of 40 , and IP$4770 \mathrm{P} *(\mathrm{EPDM}-70)$ with an ethylene content of $70 \mathrm{wt} \%$ and a Mooney Viscosity $\mathrm{ML}(1+4)$ at $125^{\circ} \mathrm{C}$ of 70 , from DuPont-Dow Elastomers, USA. *P stands for being in pellets forms. The Crosslinking was carried out with the sulfur system shown in Table 1. These additives were from Suministro de Especialidades, S.A. de C.V., Mexico. 
Table I Crosslinking system used

\begin{tabular}{ll} 
Additive & Content (phr)* \\
\hline Zinc Oxide & 5 \\
Stearic Acid & 2.5 \\
TetramethylThiuram Disulfide & $\mathrm{I}$ \\
2,2-dithio-bis-benzothiazol & 0.5 \\
Sulfur & 2 \\
\hline
\end{tabular}

*Parts of additive per hundred parts of rubber (EPDM) by weight.

\section{Compounds preparation}

TPVs were prepared in an internal mixing chamber coupled to a Brabender torque rheometer. The $\mathrm{mPP}$ and the corresponding EPDM were first premixed, without the crosslinking system, at $180^{\circ} \mathrm{C}$ and 60rpm, for 5 minutes. Then, each mix was extracted and granulated. Thereafter, each mix was again fed into the mixing chamber and processed at $165^{\circ} \mathrm{C}$ and $60 \mathrm{rpm}$, for 7 minutes, after which the crosslinking system was added and the mixing continued for 3 more minutes. A low temperature was used for the processing of these TPVs because it was found that the high viscous dissipation rubber generated at higher temperatures promote the vulcanization of rubber in the mixer, this, taking advantage of the low melting point of them PP compared to the Ziegler-Natta PP. The PP/EPDM wt \% relative concentrations studied were: 88/12, 75/25, 62/38 and 50/50. Finally, the vulcanization was carried out at $165^{\circ} \mathrm{C}$ by compression molding in order to obtain $3 \mathrm{~mm}$ thick laminates. The vulcanization time for each composition was determined in an oscillatory rheometer Rheo TECH MD+, from CG Engineering LTD, Bangkok 10900, Thailand, at $165^{\circ} \mathrm{C}$, with a rotation angle of 5 degrees.

\section{TPV characterization}

Thermogravimetric (TGA) and Differential Scanning Calorimetric (DSC) analysis: DSC analysis was carried out in a TA Instruments DSC Q200, under nitrogen atmosphere, as follows: the samples were heated up to $180^{\circ} \mathrm{C}$ in order to erase any thermal history, then cooled down to $0^{\circ} \mathrm{C}$; finally the samples were heated up to $180^{\circ} \mathrm{C}$ at $10^{\circ} \mathrm{C} / \mathrm{min}$. The degree of crystallinity of PP in all PP/ EPDM samples was taken from the ratio of the fusion enthalpy of the given sample and the fusion enthalpy of $100 \%$ crystalline pure PP, which was taken as $\Delta H_{\mathrm{PP}}=207 \mathrm{~J} / \mathrm{g} .{ }^{22}$ The TGA analysis was carried out in a Perkin Elmer TGA 4000, under nitrogen atmosphere, from room temperature up to $600^{\circ} \mathrm{C}$, at $20^{\circ} \mathrm{C} / \mathrm{min}$.

Crosslink density: Crosslink density was determined in samples immersed in toluene for 48 hours at room temperature, after which, each swollen sample was rapidly weighed. Crosslink density was calculated using the Flory-Rehner equation ${ }^{23,24}$ for the rubber phase, as shown below:

$$
\begin{aligned}
& \frac{\rho V_{s}}{M c}\left(V r^{1 / 3}-V r / 2\right)=-\left[\operatorname{Ln}(1-V r)+V r+V r^{2}\right] \\
& M c=\frac{\rho V s\left(V r^{1 / 3}-V r / 2\right)}{-\left[\operatorname{Ln}(1-V r)+V r+V r^{2}\right]}
\end{aligned}
$$

Where:
$\mathrm{M}_{\mathrm{c}}$ is the average molecular weight between crosslink points [g/ $\mathrm{mol}$,

$\mathrm{V}_{\mathrm{r}}$ is the rubber volume fraction in the swollen sample [dimensionless],

$\mathrm{V}_{\mathrm{s}}$ is the molar volume of the solvent used (106.2 for toluene) $\left[\mathrm{cm}^{3} / \mathrm{mol}\right]$,

$\rho$ is the polymer density $\left[\mathrm{g} / \mathrm{cm}^{3}\right]$,

$\chi$ is the Flory-Huggins interaction parameter; $\left(0.49\right.$ for this case $\left.^{25}\right)$

$\mathrm{V}_{\mathrm{r}}$ was calculated as follows:

$$
V r=\frac{W_{r}^{*} \rho r}{\left(W_{r}^{*} \rho r\right)+\left(W_{s}^{*} \rho s\right)}
$$

Where $\mathrm{W}_{\mathrm{r}}$ and $\mathrm{W}_{\mathrm{s}}$ represent the initial weight of the EPDM rubber and the absorbed total weight of toluene solvent, respectively, and $\rho r$ and $\rho$ s represent the rubber $\left(0.92 \mathrm{~g} / \mathrm{cm}^{3}\right)$ and solvent $\left(0.87 \mathrm{~g} / \mathrm{cm}^{3}\right)$ densities, respectively).

Mechanical properties: Tensile properties were measured in an Instron machine model 4301, according to ASTM D-638, using type A specimens; flexural properties were also measured in the Instron Machine, according to ASTM D-790; and hardness measurements were carried out with a Shore D XD instrument, according to ASTM D-2240. Each sample was tested 5 times as marked by the ASTM standards mentioned above.

\section{Results and Discussion}

\section{Vulcanization}

Vulcanization times were taken at the point where the torque curves approximated the maximum torque. From Figure 1, it can be observed that the vulcanization times for pure EPDM-55 and pure EPDM-70, are 10 and 15 minutes respectively. It can also be observed that the EPDM with higher ethylene content (EPDM-70) reaches a much higher torque, i.e. a much higher degree of crosslinking. This is assumed to be because high-ethylene containing (low propylene) EPDM is less prone to beta-scission of the main chain, than lowethylene (high propylene) containing ones. This causes the overall higher yield of crosslinks for the high-ethylene ones. ${ }^{6}$

\section{TGA and DSC analysis}

Fusion and crystallization curves of PP, in the studied PP/EPDM blends, are presented in Figure 2. It was observed that the fusion temperatures (Tm) of all PP/EPDM samples were very similar among them, but slightly higher than that of pure PP $\left(152.8^{\circ} \mathrm{C}\right)$. It can be observed from Table 2, that the blending of PP with EPDM has some influence on the crystallization process and the fusion temperature of PP. It was also observed that the crystallization temperatures (Tc) of all PP/EPDM samples were very similar among them, but slightly higher than that of pure $\mathrm{PP}\left(109.8^{\circ} \mathrm{C}\right)$.

This degree of crystallinity was found to decrease slightly with increasing rubber content (Table 2). While comparing the effect of the EPDM ethylene content, on the other hand, it was observed that Tm remained almost unaffected, whereas Tc increased as the ethylene content decreased, that is, as the propylene content increased. This can be assumed to be due to the increased compatibility of the PP towards the EPDM with the higher propylene content. It can be observed 
that in general, the crystal sizes are less heterogeneous on systems with higher ethylene content. On the other hand, and considering the difference between $\mathrm{Tm}$ and $\mathrm{Tc}$ of the samples, it was observed that the lower the $\Delta \mathrm{T}$ of the compound, the greater the thickness in the TPV crystals.

Table 2 Fusion and crystallization parameters of PP in the studied PP/EPDM blends

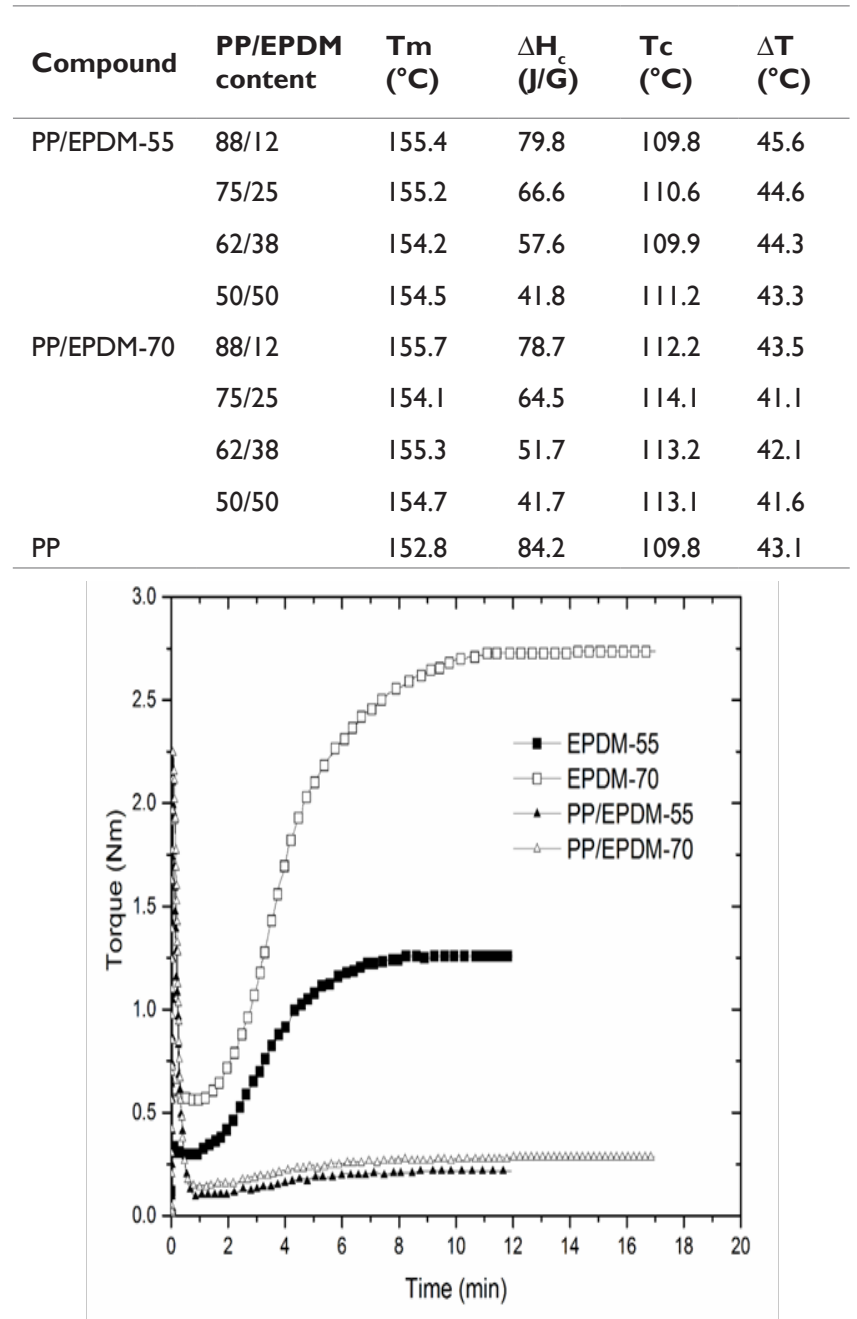

Figure I Oscilatoryrheometry of the EPDMs and the PP/EPDM (50/50) samples from which the time for the final vulcanization was taken.

With respect to the thermogravimetric analysis, Figure 3 shows that in all cases, the PP/EPDM blends present a higher thermal stability than any of the two polymers. Also, a very slight increase in the PP/ EPDM stability can be noticed as the EPDM content increases from 12 to $50 \mathrm{wt} \%$. In addition, when comparing the effect of the EPDM type, it can be observed that the EPDM with the higher ethylene content (EPDM-70) provides a slightly better thermal stability. Considering that the EPDM-70 has a slightly higher degree of crosslinking, it can be claimed that the higher degree of crosslinking as well as the higher ethylene content, contribute to the observed slightly higher thermal stability.

\section{Crosslinking density}

In this respect, it can be observed in Table 3 that, in all cases, the crosslink density slightly decreases in all cases as the rubber content increases. It is worth noting that the crosslink density is related to the EPDM part only. The largest decrease occurring as the rubber content passes from 12 to $25 \mathrm{wt} \%$; thereafter, the crosslink density varies very little among each PP/EPDM group of samples. It is also observed that the modulus "E" decreases as the crosslink density decreases. However, it is important to consider that this decrease in modulus may in part, be attributed to a decrease in the crosslink density; but also, it may in part be attributed to the decrease in the hard PP phase content in the PP/EPDM blends. In comparing the two different EPDM, it is observed that the higher ethylene content EPDM (EPDM-70) blends produced slightly higher crosslink densities.

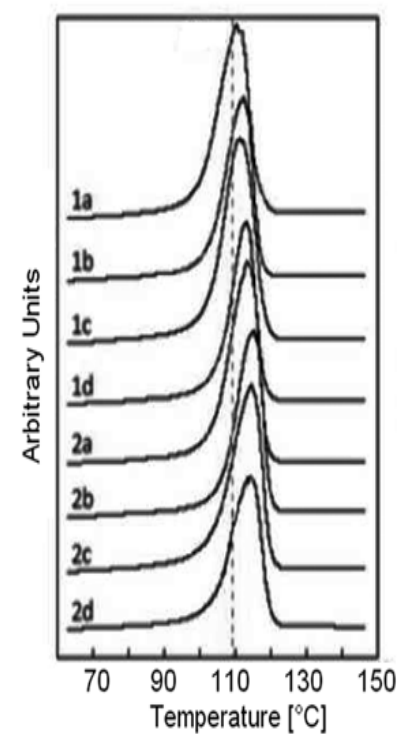

(a)

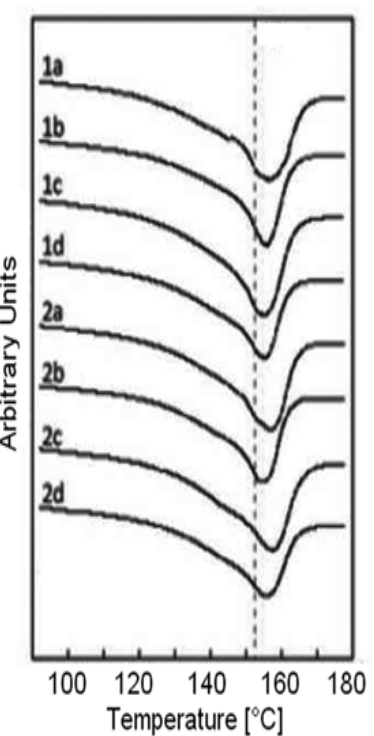

(b)
Figure 2 Crystallization (A) and fusion (B) curves for the PP/EPDM blends studied. The number on each curve refers to the EPDM; I for EPDM- 55 and 2 for EPDM-70. The letter refers to the PP/EPDM ratio; (A) 88/I2; (B) 75/25; (C) $62 / 38$; and (D) $50 / 50$.

Table 3 Crosslink density and hardness and modulus of the PP/EPDMs studied

\begin{tabular}{lllll}
\hline Compound & $\begin{array}{l}\text { PPI } \\
\text { EPDM } \\
\text { ontent }\end{array}$ & $\mathbf{V r}$ & Mc (g/mol) & E (MPa) \\
& $88 / 12$ & 0.368 & 2,076 & 1,040 \\
\hline PP/EPDM-55 & $75 / 25$ & 0.351 & 2,469 & 681 \\
& $62 / 38$ & 0.342 & 2,638 & 427 \\
PP/EPDM-70 & $88 / 12$ & 0.389 & 1,714 & $1,05 \mathrm{I}$ \\
& $75 / 25$ & 0.365 & 2,145 & 708 \\
& $62 / 38$ & 0.358 & 2,288 & 473 \\
\hline
\end{tabular}

\section{Mechanical properties}

Tensile properties of the PP/EPDM compounds are presented in Figure 4A, Figure 4B. It is observed that at each concentration, the tensile at yield, the tensile at break and the elongation at break, are slightly higher for the EPDM-70 compounds. This coincides with the slightly higher crystalline percentage in the EPDM-70. In addition, with both EPDMs, the tensile at yield decreases, whereas the tensile at break and the elongation at break increase as the softer EPDM phase content increases. 


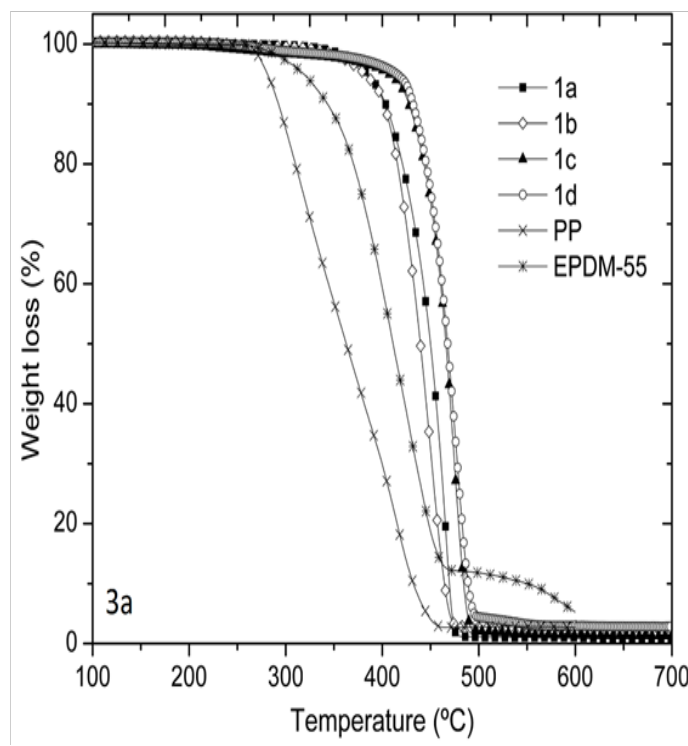

(a)

Figure 3 TGA graphs of the studied compositions. (A) EPDM-55, (B) EPDM-70.

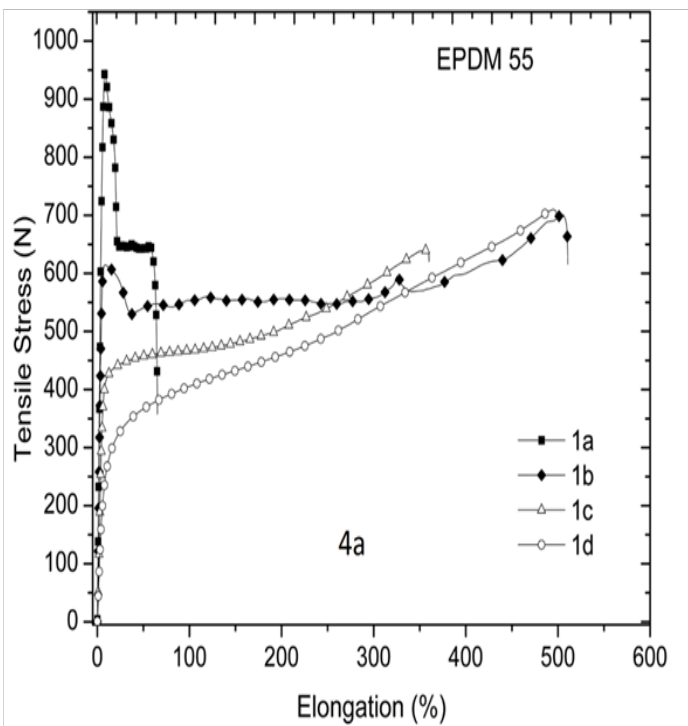

(a)

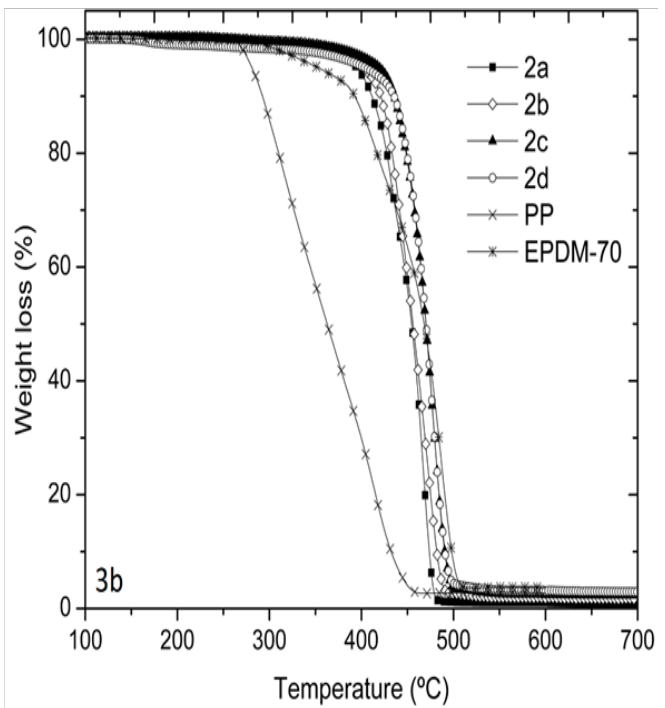

(b)

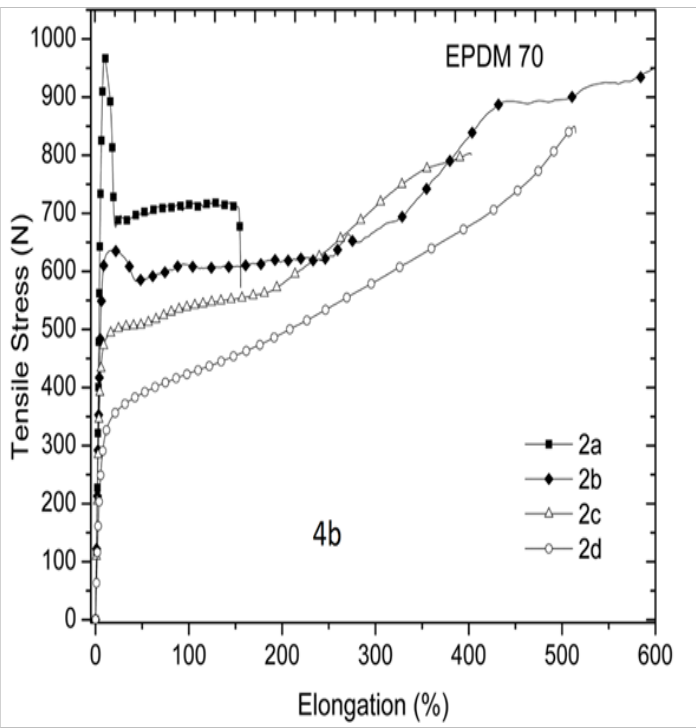

(b)

Figure 4 Stress-Strain curves of the studied PP/EPDM compounds; (A) EPDM-55 and (B) EPDM-70.

\section{Conclusion}

The blending of PP with EPDM has some influence on the crystallization process and the fusion temperature of PP. The fusion temperatures (Tm) and the crystallization temperatures (Tc) of all PP/ EPDM compounds were very similar among them, but slightly higher than that of pure PP. In addition, the degree of crystallinity of PP was found to decrease slightly as the rubber content increased.

A very slight increase in the stability of the PP/EPDM blends was noticed as the EPDM content increased from 12 to $50 \mathrm{wt} \%$. In addition, when comparing the effect of the EPDM type, it was observed that the EPDM with the higher ethylene content provided a slightly better thermal stability. The crosslink density decreased slightly as the rubber content increased. It was also observed that the modulus "E" decreased as the crosslink density decreased. However, this decrease in modulus may in part, be attributed to a decrease in the crosslink density; but also, to the decrease in the hard PP phase content in the PP/EPDM blends. In comparing the two different EPDMs, the higher ethylene content EPDM produced, in all cases, higher crosslink densities. Also, the higher ethylene content EPDM resulted with slightly higher tensile at yield, as well as tensile and the elongation at break. This coincides with the slightly higher crystalline percentage in the EPDM-70.

With respect to the concentrations used, it can be said that as the content of PPm increases, the tensile strength values increase, however, they are inversely proportional to the deformation. It should be mentioned that mixtures containing $25 \%$ of EPDM are excluded from the above, since their elastic properties do not decrease with a high concentration of PPm (75\%), suggesting that at this concentration there is a greater compatibility between phases, and a good distribution and dispersion of the rubber particles immersed in the thermoplastic phase. 


\section{Acknowledgements}

None.

\section{Conflict of interest}

The author declares no conflict of interest

\section{References}

1. Gong L, Yin B, Li L, et al. Morphology and properties of PP/EPDM binary blends and PP/EPDM/Nano- $\mathrm{CaCO}_{3}$ ternary blends. Journal of Applied Polymer Science. 2012;123(1):510-519.

2. Coran AY, Bhowmick A, Stephens H, et al. Thermoplastic Elastomeric Rubber-Plastics Blends. USA: Handbook of Elastomers; 2001. 274 p.

3. Michaeli W, Köppen H. Compounding of TPV in internal mixers. Kautschuk und Gummi Kunststoffe. 2010;63:89

4. Van Duin M. Recent developments for EPDM based thermoplastic vulcanizates. Macromolecular Symposia. 2006;233(1):11-16.

5. Naskar K, White J, De SK. Rubber Technologist Handbook. Chapter 9 Smithers Rapra, UK: Shawbury; 2009.

6. Naskar K, Noordermeer JWM. Influence of various peroxides in PP EPDM thermoplastic vulcanizates at varied blend ratios. Journal of elastomers and plastic. 2006; 38:163-180.

7. Gary VS. Ethylene-propylene elastomer. In: Mark HF, et al. editors. Encyclopedia of Polymer Science and Engineering. Canada: John Wiley; 1989.

8. De SK, Thomas S. Thermoplastic elastomers from miscellaneous rubber-plastic blends. In: De SK, et al. editors. Ellis Thermoplastic Elastomers from Rubber-Plastic Blends. Chichester, UK: Horwood Publishers; 1990. p. 233-263

9. Coran AY. Vulcanization. In: Mark JE, et al. editors. Sci and Technol of Rubber. USA: Academic Press; 1994;7:339.

10. Abdou-Sabet S, Fath MY. Thermoplastic elastomeric blends of olefin rubber and polyolefin resin. US Patent. 1982;4:311-628.

11. Coran AY, Patel R. Rubber-thermoplastic compositions. Part III. Predicting elastic moduli of melt mixed rubber-plastic blends. Rubber Chemistry and Technology. 1981;54(1):91-100.

12. Coran AY, Patel R. Rubber-thermoplastic compositions: Part IV. Thermoplastic vulcanizates from various rubber-plastic combinations. $R u b$ ber Chemistry and Technology. 1981;54(4):892-903.
13. Coran AY, Patel R, Williams D. Rubber-thermoplastic compositions Part V. Selecting polymers for thermoplastic vulcanizates. Rubber Chemistry and Technology. 1982;55(1):116-136.

14. Ilisch S, Menge H, Radusch HJ. crosslink yields in conventional and dynamic vulcanizates. Kautschuk und Gummi Kunststoffe. 2000;53:206.

15. Bazgir S, Katbab AA, Nazockdast H. Silica-reinforced dynamically vulcanized ethylene-propylene-diene monomer/polypropylene thermoplastic elastomers: Morphology, rheology, and dynamic mechanical properties. Journal of Applied Polymer Science. 2004;92(3):2000-2007.

16. Bazgir S, Katbab AA, Nazockdast H. Microstructure-properties correlation in silica-reinforced dynamically vulcanized EPDM/PP thermoplastic elastomers. Rubber Chemistry and Technology. 2004;77(1):176-191.

17. Mirzazadeh H, Katbab AA. PP/EPDM-based thermoplastic dynamic vulcanizates with organoclay: morphology, mechanical and viscoelastic properties. Polymers for Advanced Technologies. 2006;17(11-12):975980

18. Morrison NJ, Porter M. Temperature effects on the stability of intermediates and crosslinks in sulfur vulcanization. Rubber Chemistry and Technology. 1984;57(1):63-85.

19. Ezzati P, Ghasemi I, Karrabi M, et al. Rheological behaviour of PP/ EPDM Blends: the effect of compatibilization. Iranian Polymer Journal. 2008;17(9):669-679.

20. Arroyo M, Zitzumbo R, Avalos F. Composites based on PP/EPDM blends and Aramid short fibres. Morphology/behaviour relationship. Polymer. 2000;41(16):6351-6359.

21. Bocok T, Zicans J, Kalnins M. Cross-linked thermoplastic blends of polyethylene with an elastomer. Deformation and Strength Characteristics, Mechanics of Composite Materials. 2005;41(2):161-170.

22. Bu HS, Cheng SZD, Wunderlich B. Addendum to the thermal properties of polypropylene. Macromolecular Rapid Communications. 1998;9(2):75-77.

23. Barikani M, Hepburn C. Determination of crosslink density by swelling in the castable polyurethane elastomer based on 1/4-cyclohexane diisocyanate and p-Phenylene diisocyanate. Iranian J of Polym Sci and Technol. 1992;1:1.

24. Flory PJ. Statistical mechanics of swelling of network structures. The Journal of Chemical Physics. 1950;18(1):108.

25. Dudek TJ, Bueche F. Polymer-solvent interaction parameters and creep behavior of ethylene-propylene rubbers. Journal of Polymer Science Part A: Polymer Chemistry. 1964;2(2):811-822. 